\title{
Condição humana e formação virtuosa da vontade: profundezas do reconhecimento em Honneth e Rousseau'
}

Claudio Almir Dalbosco"

I- Este ensaio é parte de meu pós-doutorado, realizado no CEBRAP/SP, durante 0 segundo semestre de 2013, mediante supervisão dos professores Dr. Marcos Nobre (Unicamp) e Dr. Ricardo Terra (USP), aos quais agradeço pela recepção e liberdade para realização do trabalho, bem como pelo debate proporcionado. Também sou grato ao CNPq pela Bolsa Produtividade em Pesquisa e à Universidade de Passo Fundo (UPF/RS) por ter me concedido total liberação de minhas atividades institucionais, sem a qual não poderia ter realizado o trabalho.

II- Universidade de Passo Fundo, Passo Fundo, RS, Brasil.

Contato: vcdalbosco@hotmail.com

\section{Resumo}

Parte significativa do debate filosófico e pedagógico contemporâneo considera a teoria do reconhecimento como postura intelectual promissora para tratar de problemas filosóficos e educacionais. Nesse sentido, não se pode pensar uma ordem social justa sem o processo educacional formativo do ser humano amparado por estruturas sociais e institucionais de reconhecimento. 0 filósofo social frankfurtiano Axel Honneth tem se destacado, na atualidade, por apresentar uma teoria do reconhecimento com forte inspiração hegeliana. Contudo, em trabalho recente, intitulado Untiefen der Anerkennung (Profundezas do reconhecimento), publicado na Alemanha em 2012, inspirando-se em Frederick Neuhouser, considera Rousseau, e não mais Hegel, o pioneiro fundador da teoria do reconhecimento. 0 presente ensaio, contrapondo-se criticamente à interpretação de Honneth, possui duplo propósito: por um lado, mostrar que, se Honneth considera acertadamente Rousseau como teórico do reconhecimento, também deveria tomá-lo como pioneiro da noção de liberdade social; por outro, justificar que a profunda imbricação existente no pensamento do filósofo genebrino entre teoria do reconhecimento e educação do amor próprio só se deixa esclarecer com base em uma teoria da formação virtuosa da vontade. De outra parte, ao argumentar a favor da formação virtuosa da vontade como forma de evitar a extensão do amor próprio pervertido, Rousseau, além de tocar em um problema de fundo da condição social humana, também lança as bases para uma avaliação crítica do cenário pedagógico contemporâneo, o qual reduz perigosamente questões educacionais amplas e complexas simplesmente a problemas de aprendizagem.

\section{Palavras-chave}

Amor próprio - Reconhecimento - Formação - Vontade Virtude. 


\title{
The human condition and the virtuous education of the will: the depths of recognition in Honneth and Rousseau'
}

\author{
Claudio Almir Dalbosco"
}

I- This essay is part of my postdoctoral studies, performed at CEBRAP / SP during the second half of 2013, under the supervision of Professors Marcos Nobre (Unicamp) and Ricardo Terra (USP), whom I thank for welcoming me, for the freedom to perform this work as well as for the debate provided. I would also like to acknowledge Conselho Nacional de Desenvolvimento Científico e Tecnológico (CNPq - National Council for Scientific and Technological Development) for the research productivity fellowship and Universidade de Passo Fundo (UPF/RS) for my leave from work at the university, without which I could not have performed this study.

I- Universidade de Passo Fundo, Passo Fundo, RS, Brasil.

Contact:vcdalbosco@hotmail.com

\begin{abstract}
A significant part of the contemporary philosophical and educational discussion considers the theory of recognition as a promising intellectual approach to philosophical and educational problems. In this sense, one cannot think about a just social order without the educational process of the human being supported by social and institutional structures of recognition. At present, the Frankfurter social philosopher Axel Honneth has stood out for presenting a theory of recognition with a strong Hegelian inspiration. However, in a recent work entitled Untiefen der Anerkennung (Depths of recognition), published in Germany in 2012, drawing inspiration from Frederik Neuhouser, Honneth considers Rousseau, not Hegel anymore, the pioneer of the theory of recognition. Critically opposing Honneth's interpretation, this essay has a double purpose: on the one hand, to show that, as Honneth rightly considers Rousseau a theorist of recognition, he should also regard him as a pioneer of the concept of social freedom; and, on the other hand, to justify that the profound intertwining present in the thought of the Genevan philosopher between the theory of recognition and the education of self-love can only be clarified on the basis of a theory of the virtuous education of the will. Moreover, when arguing for the virtuous education of the will in order to avoid the extension of perverted self-love, Rousseau not only addresses a fundamental problem of the human social condition, but also lays the foundations for a critical evaluation of the contemporary educational scenario. Such scenario dangerously reduces large and complex educational issues to mere learning problems.
\end{abstract}

\section{Keywords}

Self-love - Recognition - Education - Will - Virtue. 


\section{Introdução}

Investigações recentes procuram mostrar que é Rousseau e não Hegel o fundador da teoria do reconhecimento. Entre elas, destacam-se Pathologien der Selbstliebe (Patologias do amor próprio), de Frederick Neuhouser (2012), e Untiefen der Anerkennung (Profundezas ${ }^{1}$ do reconhecimento), de Axel Honneth (2012a). Nesse seu pequeno ensaio, Axel Honneth não esconde o quanto se deixa influenciar profundamente pelo amplo e detalhado livro de Neuhouser. As pesquisas do filósofo americano permitem, em primeiro lugar, segundo Honneth, localizar a unidade do pensamento de Rousseau não mais na autodeterminação livre da vontade, como acreditou outrora Ernst Cassirer (1975), mas sim na teoria do amor próprio. Em segundo lugar, aprofundando a interpretação de Nicholas Dent, Neuhouser conclui que a tese de que o sujeito humano deve sua capacidade de ação social ao reconhecimento de outros sujeitos pertence originariamente não ao pensamento de Hegel, mas sim ao de Rousseau. A "dependência constitutiva ao outro" formaria, nesse contexto, o elo entre os resultados negativos da crítica à cultura e a versão positiva presente na ideia de um contrato social entre cidadãos e cidadãs. Sendo assim, conclui Honneth, é a teoria do reconhecimento sustentada pela teoria do amor próprio - e não mais a autodeterminação da vontade - que constitui a unidade sistemática das principais obras de Rousseau (HONNETH, 2012a, p. 48). ${ }^{2}$

Desse modo, a alta consideração que Honneth tem sobre a interpretação de Neuhouser ocorre nitidamente em detrimento da interpretação de Cassirer, pressupondo, em última instância, a incompatibilidade entre a tese da autodeterminação livre da vontade e a teoria do amor próprio. Contrariamente a

1- A tradução mais usual da expressão "Untiefen" seria abismos. Contudo, opto por profundezas porque dá mais a ideia de profundidade no sentido de inesgotável, e não enquanto algo sem fundo, como a expressão abismo poderia dar a entender.

2- Ver também a resenha crítica de Honneth sobre o livro de Neuhouser (HONNETH, 2012b).
Axel Honneth, penso que é possível reconhecer a fecundidade da contribuição de Frederick Neuhouser sem secundarizar a interpretação de Ernst Cassirer. Como procuro mostrar na parte final deste ensaio, esses dois autores não se excluem, mas sim se complementam mutuamente, pois a teoria da educabilidade do amor próprio, como forma consequente de enfrentar os perigos que lhe são inerentes, pressupõe a formação da vontade, cujos traços gerais Rousseau esboça no Émile como teoria da virtude.

0 núcleo do problema da vontade em Rousseau, considerado acertadamente por Honneth como obscuro, deixa-se esclarecer melhor - e esta é minha hipótese - quando compreendido como um problema de formação (Bildungsproblem). Ou seja, Rousseau estava certo de que a vontade humana não se explica por si mesma e nem deveria ser tomada como um conceito abstrato. No entanto, como não é absolutamente boa $^{3}$ e como é a força movente do amor próprio, ela precisa ser formada virtuosamente para que possa impulsionar as forças construtivas do amor próprio e, com isso, dominar o ímpeto destrutivo das paixões humanas. Ora, se o problema se põe realmente dessa maneira, então o Émile ocupa um lugar de maior destaque na arquitetônica do pensamento rousseauniano do que aquele concebido tanto por Honneth quanto pelo próprio Cassirer.

De qualquer modo, o fato de Axel Honneth assumir essa nova interpretação de Neuhouser traz certamente implicações decisivas para sua própria teoria da justiça, cuja última versão encontra-se formulada em seu extenso livro Das Recht der Freiheit. Grundriss einer demokratischen Sittlichkeit (Direito à liberdade. Esboço de uma eticidade democrática), publicado na Alemanha em 2011. Segundo Honneth, as teorias modernas da justiça fazem repousar sua justificação na ideia da liberdade individual, assumindo tal ideia três versões diferentes, as

3- Rousseau foi um dos autores entre os modernos que melhor reconheceu a fraqueza e a vulnerabilidade da condição humana, sabendo derivar dela também o problema da "vontade fraca". 
quais influenciam, cada uma a seu modo, as próprias teorias contemporâneas e atuais de justiça: a liberdade negativa, formulada por Hobbes; a liberdade reflexiva, esboçada por Rousseau e sistematizada diferentemente por Kant e Herder; e, por último, a liberdade social, pensada por Hegel.

Não é minha pretensão, neste breve ensaio, seguir pormenorizadamente a exposição que Honneth faz, na primeira parte de seu referido livro, de cada uma dessas três grandes concepções modernas de liberdade. Pretendo deter-me, isto sim, especificamente na implicação que tem para sua própria posição o fato de ter assumido integralmente a nova interpretação de Neuhouser. Se Honneth está de acordo com Neuhouser sobre o fato de que é Rousseau e não mais Hegel o fundador da teoria do reconhecimento, então ele deve ser levado, por coerência de sua adesão àquela interpretação, a ver em Rousseau não mais só o fundador da liberdade reflexiva - a qual Kant tomará como ponto de partida para justificar sua ideia de liberdade como autodeterminação (Selbstbestimmung) e autolegislação (Selbstgesetzgebung) -, mas, sobretudo, o fundador da própria liberdade social.

$\mathrm{Na}$ sequência, desenvolvo minha argumentação em três momentos. No primeiro, reconstruo em linhas gerais a releitura que Honneth faz, inspirando-se em Neuhouser, do pensamento de Rousseau no referido ensaio, "Untiefen der Anerkennung". No segundo momento, faço um ingresso pontual na primeira parte de sua grande obra, Das Recht der Freiheit, visando a resumir a breve interpretação que ele oferece do pensamento de Rousseau. Por fim, no terceiro momento, argumento a favor da noção de liberdade social no pensamento de Rousseau, buscando mostrar, ao mesmo tempo, em que sentido a educabilidade do amor próprio só se deixa compreender adequadamente como teoria da formação virtuosa da vontade. Essa contraposição crítica à interpretação de Honneth serve-me a uma dupla finalidade: esclarecer o sentido genuinamente formativo da ideia de educação em Rousseau e, simultaneamente, pensar o quanto tal ideia pode revelar-se ainda atual como referência crítica à redução da educação a uma "questão de aprendizagem”, que predomina no cenário pedagógico contemporâneo.

\section{Profundezas do reconhecimento}

No ensaio Untiefen der Anerkennung, Honneth, seguindo de perto as pegadas de Neuhouser ${ }^{4}$, afirma que, com a teoria do amor próprio, Rousseau transformou-se no fundador da ampla tradição da teoria do reconhecimento. Nesse sentido, o conceito de amor próprio serve não só para sua crítica à sociedade e à cultura, mas também para a fundamentação de sua teoria do reconhecimento intersubjetivo, a qual assume dupla variante, uma negativa e outra positiva. A variante negativa consiste na busca pela estima pública e pelo reconhecimento social, mas sempre tomando os outros como seres inferiores. Ou seja, essa forma de reconhecimento é negativa porque alimenta o incessante desejo humano de sempre buscar uma posição superior em relação aos seus semelhantes. Dela brota o espírito de concorrência desenfreado, movido pela vaidade ${ }^{5}$, soberba (petulância) e ódio. Essa variante predomina nos escritos de crítica à cultura e à sociedade, especialmente no Segundo Discurso. A segunda variante, por sua vez, gira em torno da noção de reconhecimento recíproco. Ela é positiva, nesse sentido, porque, além de se opor ao desejo de superioridade, fomenta o respeito recíproco entre iguais. Ela é predominante no Émile, voltando-se aí contra a variante negativa com o intuito de preparar o aluno fictício para o domínio de seu amor próprio inflamado.

4- No ensaio "Aspiração humana por reconhecimento e educação do amor próprio em Jean-Jacques Rousseau" (DALBOSCO, 2011a, p. 481496), ocupo-me em detalhes da interpretação que Neuhouser faz do amor próprio em Rousseau.

5- N. J. H. Dent, por exemplo, considera a vaidade como um dos sentimentos mais destrutivos do amor próprio, porque ela resume o desejo humano incessante de se comparar com 0 outro visando a ser superior a ele e sentir-se agraciado por tal superioridade (DENT, 1996, p. 208-209). 
Para mostrar a centralidade da teoria do amor próprio no pensamento de Rousseau, Honneth divide seu breve e denso ensaio em três partes. Na primeira, segue o desenvolvimento teórico de Rousseau até o ponto em que o genebrino põe a exigência da forma social igualitária de reconhecimento recíproco como alternativa aos aspectos danosos do amor próprio. Na segunda parte, pretende mostrar brevemente a enorme influência que a dupla variante do reconhecimento social exerceu no discurso filosófico da modernidade. Nesse contexto, escolhe as noções de história da filosofia de Kant como manifestação prototípica da primeira variante, uma vez que, segundo ele, Kant teria mostrado claramente em tais noções como a profunda necessidade humana de estima social transforma-se perigosamente na força motriz do progresso social e cultural. ${ }^{6}$ A variante positiva será desenvolvida por Fichte e Hegel na direção de uma teoria do reconhecimento do direito e da eticidade. Por fim, na última parte do ensaio, Honneth reconstrói o ceticismo crescente manifestado, segundo ele, pelo próprio Rousseau em relação à dependência ao outro que está inerente ao amor próprio. 0 filósofo genebrino teria retomado, segundo ele, sobretudo em seus escritos tardios, o argumento, com o qual também já havia se deparado no Segundo Discurso, de que talvez fosse mais aconselhável à paz da alma humana tornar-se completamente independente da consideração e do reconhecimento do outro (HONNETH, 2012a, p. 49).

Não seria menos importante seguir de perto aqui o detalhamento do argumento de Honneth nas três partes do referido ensaio, considerando a riqueza de suas ideias. Contudo, para meus propósitos, basta reconstruir agora o núcleo da primeira parte, uma vez que é nela que aparecem delineados os traços gerais da teoria rousseauniana do reconhecimento que chega a

6- Embora Honneth não aprofunde esse aspecto, é com a noção de "sociabilidade insociável" (ungesellige Geselligkeit) que Kant traz contribuição importante à filosofia social e, especificamente, ao pensamento educacional. Ocupei-me desse tema no quarto capítulo de meu pequeno livro Kant \& a educação (2011b). suas mãos por influência de Neuhouser. Nesse contexto, Honneth retoma esquematicamente a distinção entre amor de si e amor próprio, vendo no primeiro, em comum acordo com Neuhouser e o próprio Rousseau, o sentimento que o ser humano desenvolve visando a sua autopreservação. Nesse sentido, o amor de si é um sentimento pré-social, que coloca o homem natural em estado de isolamento e de quase total independência. Enquanto isso, o amor próprio refere-se ao sentimento social, pois nasce com a sociedade e impele o ser humano a comparar-se permanentemente com os outros, fazendo-o depender do julgamento daqueles. Enquanto o amor de si possui valor absoluto, o amor próprio possui valor relativo.

Como sentimento eminentemente social, o amor próprio pode assumir uma variante altamente perigosa e destrutiva, sobretudo quando a busca humana incessante pela estima pública for acompanhada pelo desejo de querer ser a qualquer custo superior aos seus semelhantes. Ora, é justamente nesse contexto que o amor próprio transforma-se nas paixões odientas e raivosas, conduzindo o ser humano ao orgulho, à vaidade e à petulância (prepotência). De outra parte, a força motriz do amor próprio pode assumir variante construtiva, culminando na ideia do reconhecimento recíproco, que é a base da cidadania republicana constituída democraticamente por seres livres e iguais. Esse é, em síntese, o núcleo da dupla variante que constitui o amor próprio e que Honneth toma de empréstimo da hermenêutica competente que Frederick Neuhouser faz do texto de Rousseau.

Com base nisso, Honneth volta-se primeiramente à variante negativa e analisa o modo como ela alimenta a crítica rousseauniana à cultura. A crítica ao teatro serve-lhe como modelo paradigmático, uma vez que, ao se voltar contra o projeto de implantação do teatro em Genebra, Rousseau teria arrolado uma gama diversificada de argumentos para mostrar em que sentido o palco simboliza o refinamento do amor próprio pervertido. Com o teatro, os cidadãos e cidadãs aprendem a 
troca de papéis, incorporando de tal forma suas características que terminam por ficar convencidos da verdade de seus novos papéis. Além disso, os atores teriam a capacidade de infectar o público com o vírus do simples parecer, transformando-o enganosamente na esfera do ser. Como atividade cultural central de sua época, o teatro aguçaria, então, segundo Rousseau, o aspecto destrutivo do amor próprio, fomentando a lógica do parecer em detrimento do ser. Sendo assim, a cultura teatral colocarse-ia na contramão da comunidade republicana, alicerçada no cumprimento do dever e nos valores de sinceridade e orgulho da cidadania (HONNETH, 2012a, p. 49-50).

Contudo, segundo Honneth, Rousseau já havia elaborado, dois anos antes, no Segundo Discurso, essa tendência cultural de afetação do aspecto destrutivo do amor próprio. Em tal escrito, já se encontra empregado o conceito de amor próprio para designar, como "segunda natureza”, esse modo de relacionamento humano surgido com a sociabilidade e que põe a busca por estima pública como base de constituição do próprio laço social. Recorrendo à Observação XV do Segundo Discurso, na qual Rousseau estabelece a famosa distinção entre amor de si e amor próprio, Honneth acentua a forma negativa que o amor próprio assume aí, como "fonte contínua do impulso, para o [ser humano] poder provar-se como superior em relação ao seu semelhante" (HONNETH, 2012a, p. 51). Ora, é justamente nessa procura incessante por superioridade em relação aos seus semelhantes que Rousseau localiza, no Segundo Discurso, a raiz de todas as patologias sociais de seu tempo. Honneth resume lapidarmente o ponto em questão:

0 que ontem ainda podia valer em relação à riqueza, ao poder e à beleza como sinal de uma superioridade individual, deve hoje ser novamente sobrepujado em razão da ampliação social, de tal modo que domina em todos os campos de concorrência uma tendência de elevação incontrolável da conduta de distinção (HONNETH, 2012a, , p. 52).

Em resumo, como atestam então o Segundo Discurso e a Carta a D'Alambert, Rousseau deixou-se orientar, em sua ampla crítica à cultura, pela variante negativa do amor próprio: a busca incontrolável por superioridade e a obsessão pela distinção em relação aos seus semelhantes são duas tendências que formam a dinâmica destrutiva do desenvolvimento cultural humano.

Contudo, no Émile, a variante positiva assume sua dianteira, mostrando com isso a insatisfação do filósofo em relação ao aspecto prejudicial e destrutivo do amor próprio. Honneth reconhece que não é tão fácil assim para Rousseau provocar a passagem do aspecto negativo para o positivo do amor próprio. Segundo ele, para que tal passagem pudesse ser efetuada com força e mais clareza, Rousseau deveria ter acentuado as condições mediante as quais a necessidade patológica do ser humano de mostrar sua superioridade em relação aos seus semelhantes ficasse suprimida pelo autojulgamento mediado intersubjetivamente (HONNETH, 2012a, p. 5253). Em outros termos, a variante positiva do amor próprio toma efetivamente a dianteira em passagens do Émile onde fica estabelecido o respeito recíproco como vetor da sociabilidade humana. É nessas passagens que Rousseau traça o ideal formativo do Emílio, mostrando o quanto a simplicidade e a moderação são decisivos para sua formação virtuosa, voltando-se contra a vaidade e a soberba.

Testemunhos da variante positiva do amor próprio são, então, exatamente aquelas passagens do Émile nas quais Rousseau procura enfrentar o inevitável problema da educação do amor próprio de seu aluno fictício. Para Honneth, o núcleo dessa tarefa educativa repousa na proposta feita por Rousseau de "ampliação" do amor próprio até a virtude. Assim argumenta ele: "Falar sobre a ampliação do amor próprio significa então precisamente 
familiarizar os sujeitos com a concepção de que eles precisam do reconhecimento social recíproco e, por isso, devem renunciar ao espírito forte de concorrência que visa à superioridade" (HONNETH, 2012a, p. 53).

Portanto, mostrando ao seu aluno fictício a importância da dependência recíproca, Rousseau queria evitar que seu amor próprio fosse infectado pelo vírus da soberba e do desejo de superioridade (vontade de dominação). Com isso, encontrou a forma temperada do reconhecimento social na expressão "respeito entre iguais", pondo-a como alternativa à tendência destrutiva do amor próprio. Desse modo, pela interpretação de Honneth, podemos ver que "dependência recíproca" e "respeito entre iguais" constituem o núcleo da educabilidade do amor próprio, pois são esses dois aspectos que, segundo Rousseau, impedem que a variante negativa do amor próprio assuma a dianteira na formação do aluno fictício.

Ora, segundo Honneth, secompreendermos desse modo o tratamento pedagógico oferecido por Rousseau ao amor próprio no Émile, não será tão difícil entender os motivos que fazem o filósofo genebrino aparecer em geral, na atualidade, como teórico do reconhecimento. Além da vontade de dominação (busca obsessiva pela posição superior em relação aos demais), o amor próprio é constituído pela necessidade de "se fazer valer como alguém aos olhos de seus parceiros sociais e poder desfrutar com isso uma forma de valor social" (HONNETH, 2012a p. 53). Não há dúvida que Honneth toca aqui no aspecto crucial do pensamento de Rousseau e que está no centro de sua concepção de justiça e dignidade humana. Dent, grande especialista em Rousseau no âmbito da pesquisa anglo-saxônica, sintetiza isso de maneira clara por meio do conceito de "personalidade moral". Assim afirma ele: "A 'personalidade moral', no entender de Rousseau, é a necessidade humana fundamental para cada pessoa de ser reconhecida e respeitada por outros como alguém que importa e que tem valor e dignidade sem depender de ninguém" (DENT, 1996, p. 149).
0 importante, para meu ponto, é que Honneth destaca o papel indispensável que a variante positiva desempenha no pensamento de Rousseau, formando o alicerce de sua teoria educacional. Sob esse aspecto, vale a pena traduzir na integra uma passagem de seu referido ensaio, que resume bem seu argumento:

Rousseau está sendo muito consequente quando expõe, em sua obra educacional, os critérios pedagógicos que disponibilizam aos adultos, desde sua mais tenra idade, a consciência sobre a igualdade social. Pois, somente quando o indivíduo aprende a se considerar como igual entre iguais, é que ele pode se compreender simultaneamente como colaborador daquele "outro generalizado”, de cuja formação do juízo ele próprio depende para a satisfação de seu amor próprio (HONNETH, 2012a, p. 54).

Ou seja, por ser considerada como valor insubstituível, a igualdade social precisa fazer parte do mundo do ser humano já em sua primeira infância. Mais uma vez, torna-se claro o quanto é importante, para a formação do aluno fictício, a consciência sobre a dependência social e o respeito recíproco entre iguais, pois são esses dois aspectos que propiciam uma satisfação positiva do amor próprio e, com isso, da realização pessoal do próprio sujeito.

Em conclusão, a reconstrução acima nos dá uma ideia geral do quanto a teoria da ambiguidade do amor próprio, mediada pela interpretação de Neuhouser, foi capaz de alterar significativamente a posição de Honneth, a tal ponto que o levou a considerar, sem maiores dificuldades, Rousseau como fundador da teoria do reconhecimento. Muito longe estamos aqui, então, daquele Rousseau simplesmente enquadrado na formulação da liberdade reflexiva e como puro pioneiro intelectual da distinção entre heteronomia e autonomia. Reconstruir brevemente como Honneth formula essa sua apreciação convencional do pensamento do genebrino em seu livro $O$ direito $\dot{a}$ liberdade é o objetivo do tópico seguinte. 


\section{Rousseau como fundador da liberdade reflexiva}

No prefácio de $O$ direito à liberdade, Axel Honneth revela que, embora o trabalho nessa obra tenha lhe custado cinco longos anos, ao terminá-la, teve o impulso, percebendo sua incompletude, de querer iniciá-la novamente. De qualquer forma, trata-se de um trabalho extenso, de muita coesão e profundidade argumentativa, representando sem dúvida um estágio avançado na maturidade intelectual do autor. Sem correr o risco de cair no pedantismo, esbanja erudição, passando em revista várias tradições filosóficas, políticas e jurídicas, tanto modernas como contemporâneas.

A consideração a Rousseau ocupa um lugar infınitamente pequeno na exposição de Honneth, considerando, por um lado, a enorme extensão da obra e, por outro, o papel destacado que o pensamento do genebrino desempenha no cenário filosófico da modernidade. Não seria nada descabido imaginar, caso Honneth desejasse realmente reescrever essa sua grande obra, não só o lugar de maior destaque que daria a Rousseau, como também o modo diferente como abordaria o pensamento do genebrino. De qualquer sorte, Rousseau é tratado aí como pioneiro intelectual da liberdade reflexiva, sendo considerado, mais precisamente, como teórico originário da autonomia da vontade e como fundador da distinção entre ação heterônoma e ação autônoma. Ou seja, como verdadeiro precursor de Kant, passa longe da noção de liberdade social. Antes de reconstruir em detalhes esse núcleo da interpretação de Honneth, preciso inseri-la, resumidamente, nos propósitos mais amplos de sua grande obra, $O$ direito à liberdade.

A primeira parte do livro $O$ direito $\dot{a}$ liberdade é dedicado à "apresentação histórica" da liberdade individual. 0 autor compreende por liberdade individual a autonomia do indivíduo, concebendo-a como valor ético dominante da sociedade moderna, que impregna também decisivamente sua ordem institucional. 0 pensamento da autonomia tornou-se tão poderoso na modernidade porque foi o único valor ético capaz de vincular sistematicamente o si mesmo (Selbst/Self) e a ordem social. Sendo assim, do mesmo modo como a liberdade individual oferece representações da ideia do bem ao indivíduo, ela também oferece indicações para uma ordem social legítima (HONNETH, 2012a, p. 36). Fica posta então, desse modo, a exigência do nexo estreito entre liberdade individual e justiça social e, mais precisamente, a exigência de que qualquer representação de justiça precisa ser remetida à autodeterminação individual.

Se a ideia de justiça depende do esclarecimento da noção de liberdade individual, então é precisamente sua diferenciação tripartite na modernidade que deve ser investigada. Ora, é na pesquisa dos três modelos que constituem a liberdade individual que Honneth se volta ao pensamento de Rousseau. Antes disso, ele oferece uma exposição resumida de Hobbes, tomando-o como exemplo do modelo negativo de liberdade. Hobbes teria oferecido, aos seus olhos, um modelo negativo de liberdade porque a concebeu como independência das coações externas, justificando com base nisso o sistema social do egoísmo.

No que diz respeito à liberdade reflexiva, Rousseau é tomado como seu pioneiro intelectual, estando na origem das duas versões elaboradas posteriormente: liberdade reflexiva como autolegislação (Kant) e como autorrealização (Herder). Para justificar essa inserção de Rousseau na concepção reflexiva de liberdade, Honneth toma "a profissão de fé do vigário saboiano” como referência textual. É nesse longo interlúdio inserido no livro quarto do Émile que Rousseau discute dois temas que serão decisivos para o desenvolvimento posterior da liberdade reflexiva, principalmente para a sua versão kantiana: o tema da vontade e, diretamente vinculado com ele, o da distinção entre ação heterônoma e ação autônoma. Esses dois temas estão sustentados pela tese, formulada textualmente em Do Contrato Social, de que o sujeito é livre somente quando pode 
determinar a si mesmo. Ou seja, de acordo com essa obra jurídica e política de Rousseau, vontade livre é aquela que pode dar-se a si mesma a lei.

"A profissão de fé do vigário saboiano" torna-se importante aos propósitos de Honneth porque é aí que Rousseau abordaria, segundo ele, as transformações necessárias ao conceito de natureza humana para poder justificar a autonomia da vontade. Nesse sentido, seu ponto de partida consiste em abordar a natureza humana como constituída pela tensão entre vontade e desejo, e a questão pedagógica moral decisiva, formulada no livro quarto do Émile, consiste em saber como o aluno fictício pode ser educado para a autodeterminação. Desse modo, Honneth não ignora em sua abordagem que o núcleo do projeto educacional dessa obra pedagógica rousseauniana repousa na formação humana para a maioridade. Segundo ele, é nesse contexto que se põe o problema da liberdade e da autonomia da vontade, remetendo tal problema diretamente à distinção entre heteronomia e autonomia.

Considerando a definição de natureza humana e o problema da determinação (autonomia) da vontade, Honneth define ação heterônoma como aquela que se deixa orientar pelas inclinações sensíveis. Ela não é livre porque depende das "leis do corpo", isto é, da causalidade natural. Sem ter as forças suficientes para dominar suas paixões, o ser humano não age de acordo com sua própria vontade, cedendo a todo o momento ao poder de suas inclinações. Estando vulnerável aos seus desejos, ele distancia-se da ação virtuosa. 0 autor define ação autônoma, por sua vez, como aquela que segue o que é determinado pela vontade e não pelos desejos. No entanto, entre ação e vontade se interpõe a lei, sendo a vontade livre aquela que se deixa determinar pela lei que ela dá a si mesma. Nesse sentido, a autonomia da vontade permite ao sujeito que realize em sua ação aquilo que originariamente era sua intenção, ou seja, o que ele próprio escolheu de maneira racional e livre (HONNETH, 2012a, p. 61).

Em síntese, Rousseau antecipa o núcleo da versão reflexiva de liberdade, na medida em que a faz repousar na capacidade da vontade dar a si mesma a lei (ideia de autolegislação). Ele formulou tal definição com base na distinção entre vontade e desejo, fazendo resultar dela também a distinção entre ação heterônoma e ação autônoma. Uma vez resumido o núcleo da interpretação que Honneth faz de Rousseau em $O$ Direito à liberdade, pretendo mostrar, na sequência, que se Rousseau, como o próprio Honneth comprovou, é o teórico do reconhecimento, não pode ser tomado tão só como precursor da liberdade reflexiva. Também pretendo dar um passo além, mostrando que a educabilidade do amor próprio depende, como modo de enfrentamento da destrutividade do amor próprio, da formação virtuosa da vontade.

\section{Formação da vontade como educação do amor próprio}

$\mathrm{Na}$ parte final do ensaio, pretendo assinalar minha crítica ao tratamento oferecido por Honneth a Rousseau em sua obra Das Recht der Freiheit, baseando-me em duas ideias: a primeira ampara-se na identificação entre aquilo que Honneth concebe como variante positiva do amor próprio e a concepção de liberdade social que ele reconstrói do pensamento de Hegel; a segunda ideia refere-se ao vínculo entre educabilidade do amor próprio e formação virtuosa da vontade.

No que diz respeito à primeira ideia, o próprio Honneth já deixa entender, em seu ensaio Untiefen der Anerkennung, embora sem seguir firmemente nessa direção, que o Rousseau teórico do reconhecimento estaria muito próximo da concepção de liberdade social. No entanto, para que possamos torná-la uma direção segura, basta acentuar a semelhança existente entre, por um lado, a definição oferecida por ele do reconhecimento recíproco no referido ensaio e, por outro, a noção hegeliana de liberdade 
social que apresenta no livro Das Recht der Freiheit. A meu ver, ambas convergem na noção de "respeito mútuo entre iguais", pois o que Rousseau concebe como variante positiva do amor próprio no Émile antecipa a própria exigência do "ser para si mesmo em outro", que Hegel põe como condição da liberdade social. Desse modo, ambos, Rousseau e Hegel, compartilham a mesma tese de que a ação virtuosa só pode ocorrer de forma cooperativa, na vida em sociedade. No caso especificamente de Rousseau, são as misérias comuns e a fraqueza do ser humano que o impelem à vida social e à humanidade. Ele deixa isso claro na seguinte passagem do livro quarto do Émile:

\section{É a fraqueza do homem que o torna sociável; são nossas misérias comuns que incitam nossos corações à humanidade: nada lhe deveríamos se não fôssemos homens. Todo o apego é sinal de insuficiência: se nenhum de nós tivesse necessidade de outrem, não pensaria em unir-se a ninguém (ROUSSEAU, 1992, p. 246). ${ }^{7}$}

Portanto, o vetor da sociabilidade virtuosa consiste aqui, de acordo com essa passagem, não na vontade do ser humano de querer buscar incessantemente uma posição superior em relação aos outros, deixando-se mover pela vaidade e ambição desmesurada (variante negativa do amor próprio). Repousa sim na condição humana frágil e vulnerável, pois é daí que brota o próprio sentimento de humanidade que une todos os seres humanos entre si. ${ }^{8}$ Orientar a educação do jovem Emílio na direção de uma vontade virtuosa, que repousa

\footnotetext{
7- No original: "C'est la faiblesse de I'homme qui le rend sociable: ce sont nos misères communes qui portent nos coeurs à l'humanité, nous ne lui devrions rien si nous n'étions pas hommens. Tout attachement est um signe d'insuffisance: si chacun de nous n'avoit nul besoin des autres il ne songeroit guères à s'unir à eux" (OC IV, 503).

8- Martha Nussbaum interpreta o problema na mesma direção: "Na teoria da educação de Rousseau, 0 aprendizado sobre a debilidade básica do ser humano é um elemento central, pois só o reconhecimento desta debilidade nos permite transformar-nos em seres sociais e, portanto, formar a humanidade" (NUSSBAUM, 2010, p. 60).
}

nesse sentimento de humanidade, é uma das principais tarefas do livro quarto do Émile.

Em sintese, segundo a concepção rousseauniana, não pode existir sujeito virtuoso fora da sociedade, uma vez que a ação virtuosa depende sempre de estruturas sociais de reconhecimento. Tudo isso constitui, posteriormente, a base da filosofia social de Hegel, antecipada, no entanto, originariamente, em seus traços gerais, pela teoria rousseauniana do amor próprio. Portanto, se Honneth, ao escrever sua grande obra Das Recht der Freiheit, já tivesse interpretado Rousseau como teórico do reconhecimento e prestado cuidadosa atenção ao aspecto construtivo do amor próprio, certamente o teria concebido também como pioneiro da concepção social de liberdade.

De outra parte, embora existam muitas semelhanças entre Rousseau e Hegel, não posso deixar de assinalar uma diferença importante. A "Profissão de fé do vigário saboiano" não desenvolve um programa detalhado de como a liberdade se encarna nas instituições éticas e como seria por elas realizada. Trata-se aí, é verdade, de preparar o ingresso virtuoso do jovem Emílio na sociedade, mas não na forma de uma exposição das instituições sociais e da suposta eticidade a elas inerente. Rousseau é extremamente crítico em relação ao espírito cultural e científico, não vendo com bons olhos o estado em que se encontravam as instituições sociais e culturais de sua época. Também é preciso considerar, nesse contexto, que, embora Rousseau não tenha desenvolvido obviamente uma filosofia do direito nos termos hegelianos, antecipou, contudo, a meu ver, aspectos decisivos dela como propedêutica formativa da vontade do aluno fictício, colocando em sua base o exercício da virtude.

Uma passagem do livro quarto do Émile ilustra bem essa ideia: "o exercício das virtudes sociais leva ao fundo dos corações o amor à humanidade: é fazendo o bem que nos tornamos bons; não conheço nenhuma prática mais segura” (ROUSSEAU, 1992, p. 284). ${ }^{9}$ Ou seja, em

9- No original: "l'éxercice des vertus sociales porte au fond des coeurs l'amour de l'humanité; c'est en faisant le bien qu'on devient bon, je ne connais point de pratique plus sure" (OC IV, 543). 
outros termos, é por meio da prática da virtude que podemos cristalizar em nossos corações o amor à humanidade e, com isso, tornarmo-nos sujeitos justos, uma vez que Rousseau considera a justiça como a virtude principal.

Por fım, volto-me agora para a imbricação entre educação do amor próprio e formação moral da vontade. Como já afırmei antes, Honneth, ao conceber desde o início a interpretação de Neuhouser como contrária à posição de Cassirer, assume a teoria do amor próprio sem dar a devida atenção ao problema da formação virtuosa da vontade e, com isso, tangencia o aspecto nuclear do projeto educacional do Émile. Sendo assim, não consegue extrair todas as consequências que a teoria da educabilidade do amor próprio possui para pensar uma ordem social justa. Ele incorre nesse limite porque padece do mesmo pathos de outras grandes interpretações do pensamento de Rousseau que tendem a considerá-lo somente a partir Do Contrato Social, não sendo capazes, desse modo, de vincular os problemas jurídicos e políticos aí contidos com o indispensável problema da formação virtuosa da vontade. Elas ignoram, portanto, o quanto o direito e a política são profundamente devedoras, no pensamento de Rousseau, de uma teoria da virtude.

É bem verdade que, como vimos, Axel Honneth não desconsidera, de modo algum, a importância do Émile, sobretudo, porque, segundo ele, inspirando-se na interpretação de Frederick Neuhouser, é nessa obra que Rousseau vê na educação do amor próprio a maneira mais eficaz de enfrentar a corrupção social e a barbarização da moral diagnosticadas nos escritos de crítica à cultura. Honneth põe-se também na direção certa quando concebe a ampliação do amor próprio até a virtude, concebendo-a como solução encontrada por Rousseau para tratar da periculosidade do amor próprio.

Contudo, permanece a meio caminho quando atribui somente ao reconhecimento social recíproco a força capaz de ampliar o amor próprio até a virtude. Ignora, com isso, que, na arquitetônica pedagógica de Rousseau, o aluno fictício só adquire consciência sobre a importância do respeito recíproco entre iguais por meio do longo, tenso e inesgotável processo educativo de seu amor próprio, o qual depende da capacidade de determinação da vontade. Talvez por se deixar intimidar pela obscuridade do conceito rousseauniano de vontade ou por ter visto nele somente a sombra kantiana projetada por Cassirer, ignorou que foi justamente na educação virtuosa da vontade que Rousseau pensou ter encontrado o principal antídoto à variante negativa do amor próprio.

Podemos nos perguntar agora: por que a educabilidade do amor próprio depende da formação da vontade? Um ingresso pontual no Émile é indispensável para esclarecer essa questão. Nesse texto, como em outras obras de Rousseau, o amor próprio é concebido com um dos principais sentimentos humanos, que pode inclinar-se tanto aos vícios quanto à virtude. Essa dupla direção (inclinação) constitui o núcleo da própria teoria da ambiguidade do amor próprio. Contudo, por ser um sentimento, o amor próprio não pode agir por si mesmo, precisando ser, nessa condição, impulsionado por outra coisa. Ora, a vontade significa exatamente esse impulso, tornando-se, desse modo, a força movente do amor próprio. Quando dirigida construtivamente, essa força tornase virtude. Desse modo, a virtude nada mais é do que o impulso ético da vontade, fazendo o amor próprio canalizar suas forças (paixões) na direção construtiva. Ou seja, quando é movido pelo amor à justiça, o amor próprio torna-se cooperativo e solidário, deixando de ser vaidoso e petulante, enfim, egoísta.

Rousseau torna isso claro em uma passagem importante do Émile, localizada quase ao final dessa obra. Assim afirma ele: "A palavra virtude vem de força; a força é a base da virtude; a virtude só pertence a um ser fraco por natureza e forte por sua vontade; é só nisso que consiste o mérito do homem justo [...]" ( ROUSSEAU, 1992, p. 535). ${ }^{10}$ Com isso, fica claro, então, que a

10- No original: "Le mot vertu vient de force; la force est la base de toute vertu. La vertu n'appartient qu'à un être faible par sa nature et fort par sa volonté; c'est en cela que consiste le mérite de l'homme juste [...]" (OC IV, 817). 
virtude (justiça) brota da ação dirigida pela força da vontade e não pelo impulso dos desejos e inclinações. A própria justiça, como uma virtude cardinal da teoria moral rousseauniana, repousa na força da vontade. Podemos ver, com isso, o quanto a orientação normativa dessa força movente torna-se decisiva, pois, se for dirigida pela virtude (justiça), também proporcionará uma ampliação construtiva do amor próprio. Portanto, o vínculo da teoria do amor próprio com a formação virtuosa da vontade é o núcleo do pensamento filosófico e pedagógico de Rousseau, porque serve tanto para "corrigir" a tendência pessimista de seus escritos de crítica à cultura quanto para oferecer a base formativoeducacional necessária aos ideais normativos que sustentam a concepção antropológica, política e jurídica do genebrino.

Justamente nesse contexto é que se deixa compreender a afirmação da "ampliação do amor próprio”, que Honneth considera acertadamente como aspecto central da contraposição à variante negativa do amor próprio. Assim se expressa Rousseau: "Estendamos o amor próprio sobre os outros seres, nós o transformaremos em virtude, e não há coração humano em que essa virtude não tenha sua raiz" (ROUSSEAU, 1992, p. 288). ${ }^{11}$ Ou seja, a ideia da ampliação do amor próprio implica a ruptura com sua própria perspectiva individualista egocêntrica, exigindo que o ser humano inclua em sua própria ação o ponto de vista dos outros. Mas Honneth se ateve somente à ampliação do amor próprio, desconhecendo que essa teoria positiva da virtude é precedida, na arquitetônica pedagógica do Émile, por uma teoria negativa da virtude, a qual tem como meta principal a "contenção" do amor próprio na fase educativa inicial do aluno fictício. Uma breve referência a essa dupla teoria da virtude é indispensável para ver o quanto a formação da vontade torna-se a força movente da educabilidade do amor próprio e quanto a

11- No original: "Etendons l'amour-propre sur les autres êtres, nous le transformerons em vertu, et il n'y a point de coeur d'homme dans lequel cette vertu n'ait sa racine" (ROUSSEAU, 1959-1995, p. 547). interpretação de Honneth é, nesse aspecto, parcial e restritiva.

Cabe resumir agora, então, esquematicamente, em forma de conclusão, como essa dupla teoria da virtude ganha forma na arquitetônica pedagógica do Émile. Enquanto a exposição da teoria negativa da virtude ocorre nos três primeiros livros, a teoria positiva ocorre nos livros quarto e quinto do Émile. Cada um desses dois momentos contém muitos problemas filosóficos e pedagógicos, mostrando o quanto Rousseau se aprofundou na compreensão da condição humana e na análise da sociedade de sua época e, por fim, o quanto apostou na formação da vontade como núcleo diretivo da educabilidade do amor próprio.

Primeiro, sobre a teoria negativa da virtude. Não sendo ela a formação moral propriamente dita, serve sim como sua propedêutica, uma vez que tem como tarefa principal ensinar o educando fictício a evitar os vícios. A teoria negativa da virtude, constituindo o núcleo da educação natural ${ }^{12}$ como educação negativa, assenta-se no princípio pedagógico da educação pelas coisas, dependendo, nesse sentido, da arte de encenação pedagógica do educador. ${ }^{13}$ Desse modo, o processo de reconhecimento recíproco que ocorre nesse âmbito da arquitetônica pedagógica restringe-se consideravelmente à relação entre educador e educando. Rousseau faz propositalmente essa restrição porque acredita que a fase da infância - abrangendo primeira, segunda e terceira infância -, deve ser de quase inatividade do amor próprio. Desse modo, é tarefa da educação natural postergar pelo menos até a puberdade o florescimento do amor próprio, coibindo com isso que sua dimensão inflamada e venenosa assuma a dianteira na formação do si mesmo do educando.

12- Tratei sistematicamente desse tema no meu livro Educação natural em Rousseau (DALBOSCO, 2011c).

13 - Ou seja, Rousseau concebe como tarefa principal do educador criar os cenários pedagógicos adequados, levando em consideração, sobretudo nessa fase em que 0 educando se encontra, 0 ambiente natural, envolvendo passeios na floresta, caminhadas no campo e brincadeiras no escuro. Sobre esse tema, ver a exposição oportuna de Alfred Schäfer (2002, p. 94). 
Em sintese, a teoria da virtude ocupa-se nessa fase da justificação do aspecto natural e negativo da educação. Tal aspecto é natural porque o que está em jogo na educação do aluno fictício é a formação de noções básicas sobre o que são suas necessidades naturais e quais são os modos mais adequados de satisfazê-las. 0 núcleo das relações educativas é orientado aí pela tensão entre as necessidades da criança e os cuidados do adulto. De outra parte, o aspecto dessa educação é negativo porque não se trata ainda de ampliar o amor próprio até a virtude, mas de contê-lo em relação aos vícios. Contudo, o que em princípio aparece só como negativo nessa "contenção" do amor próprio, converte-se, nos três primeiros livros do Émile, numa dimensão positiva, pois ela está a serviço do desenvolvimento de outras capacidades (potencialidades) do educando, transformando-se na propedêutica da posterior formação virtuosa da vontade do aluno fictício. É nesse sentido que a teoria negativa da virtude assume a forma de uma "física experimental", cuja tarefa principal consiste em fortalecer o corpo e refinar os sentidos do educando. Ora, o fortalecimento do corpo e o refinamento dos sentidos, além de constituírem a propedêutica da formação virtuosa da vontade, funcionam também como mecanismo poderoso de preparação do terreno para a germinação futura da consciência cidadã, indispensável ao exercício republicano democrático de iguais entre iguais.

Por fim, no que diz respeito à formação virtuosa da vontade, seu coração localiza-se no livro quarto do Émile, sendo também complementado, em sua dimensão política, pelo livro quinto. Há aqui uma mudança substancial em relação à teoria negativa da virtude, pois a formação do jovem Emílio ocorre num contexto educacional ampliado, não mais restrito à relação tripartite entre educando, educador e natureza. Trata-se, na verdade, de pensar sua formação num contexto marcado pela dupla e significativa ampliação: do amor próprio e da sociedade. Na condição de pleno florescimento de seu amor próprio, Emílio percebe o quanto se ampliam diante de si tanto a ação social quanto a teia institucional que constitui a sociedade como um todo. 0 intenso desenvolvimento de seu amor próprio, representado pela explosão de suas paixões, é acompanhado pela possibilidade real de ampliação da esfera pública destinada à sua ação. É justamente aí que a formação virtuosa da vontade assume o papel de timoneiro no sentido de orientar as paixões e, com isso, contribuir para que predomine a variante construtiva do amor próprio.

Rousseau esboça o "programa" de formação virtuosa da vontade de maneira meio tortuosa, recorrendo a um conteúdo assistemático, formado por teses e princípios polêmicos. Para o que interessa agora ao meu ponto, cabe destacar que seu núcleo repousa no “amor à humanidade", materializado pelo amor à justiça. Como ele próprio afirma: "o amor ao gênero humano não é outra coisa em nós senão o amor à justiça” (1992, p. 288). 0 amor à justiça torna-se uma virtude poderosa capaz de canalizar construtivamente a força do amor próprio na direção do respeito recíproco entre iguais. Desse modo, vontade virtuosa é aquela capaz de assegurar a igualdade nas relações humanas e sociais, pois Rousseau está convicto de que é pelo princípio da igualdade que se pode assegurar a justiça na vida republicana. ${ }^{14}$

Com o arrazoado acima, penso ter deixado claro, por um lado, o quanto a educabilidade do amor próprio depende da formação virtuosa da vontade e, por outro, o quanto o reconhecimento recíproco entrelaça-se com a concepção de liberdade social. Sendo assim, fica reafirmada uma dupla conclusão, já antecipada na introdução do ensaio: a primeira é de que Rousseau só pôde fundar a teoria do reconhecimento porque formulou embrionariamente uma concepção de liberdade social. A segunda conclusão confirma a ideia de que as interpretações de Cassirer e Neuhouser,

14- Na atualidade, John Rawls (2012), também se deixando influenciar fortemente pela teoria do amor próprio de Neuhouser, considera o princípio da igualdade como núcleo da teoria da justiça de Rousseau. 
ao contrário do que afirmou Honneth, depende de um amplo "programa" de formação complementam-se mutuamente, pois, como da vontade, duplamente esboçado, como teoria acabei de mostrar, a educação do amor próprio negativa e positiva da virtude.

\section{Referências}

CASSIRER, Ernst. Das Problem Jean Jacques Rousseau. Darmstadt: WBG, 1975.

DALBOSCO, Claudio Almir. Aspiração humana por reconhecimento e educação do amor próprio em Jean-Jacques Rousseau. Educação e Pesquisa, São Paulo, v. 37, n. 3, p. 481-496, jan./dez. 2011a.

DALBOSCO, Claudio Almir. Kant \& a educação. Belo Horizonte: Autêntica, 2011b.

DALBOSCO, Claudio Almir. Educação natural em Rousseau: das necessidades da criança e dos cuidados do adulto. São Paulo: Cortez, 2011c.

DENT, Nicholas J. H. Dicionário Rousseau. Rio de Janeiro: Jorge Zahar, 1996.

HONNETH, Axel. Das Recht der Freiheit: grundriss einer demokratischen Sittlichkeit. Frankfurt am Main: Suhrkamp, 2011.

HONNETH, Axel. Die Entgiftung Jean-Jacques Rousseau. Neuere Literatur zum Werk des Philosophen. Deutsche Zeitschrift für Philosophie, v. 60, n. 4, p. 611-632, 2012b.

HONNETH, Axel. Untiefen der Anerkennung: Das sozialphilosophische Erbe Jean-Jacques Rousseau. WestEnd, Neue Zeitschrift für Sozialforschung, v. 9, n. 1-2, p. 47-64, 2012a.

NEUHOUSER, Frederick. Pathologien der Selbstliebe: Freiheit und Anerkennung bei Rousseau. Frankfurt am Main: Suhrkamp, 2012.

NUSSBAUM, Martha. Sin fines de lucro: por qué la democracia necesita de las humanidades. Buenos Aires: Katz, 2010.

RAWLS, John. Conferências sobre a história da filosofia política. São Paulo: Martins Fontes, 2012.

ROUSSEAU, Jean-Jacques. Oeuvres complètes. Paris: Gallimard: Bibliothèque de la Plêiade, 1959-1995. 5 tomos.

ROUSSEAU, Jean-Jacques. Emílio ou da educação. Rio de Janeiro: Bertrand Brasil, 1992. Tradução de Sérgio Milliet.

SCHÄFER, Alfred. Jean-Jacques Rousseau: ein pädagogisches Porträt. Weinheim/Basel: Beltz Verlag, 2002.

Recebido em: 27.09.2013

Aprovado em: 07.03.2014

Claudio Almir Dalbosco é professor titular do curso de filosofia e do Programa de Pós-graduação da Universidade de Passo Fundo (UPF/RS). 